DOI: $10.2478 / \mathrm{v} 10077-010-0013-1$

\author{
A. Zieliński, S. Sobieszczyk, T. Seramak, W. Serbiński, B. Świeczko-Żurek, \\ A. Ossowska \\ Technical University of Gdansk, Faculty of Mechanical Engineering, Narutowicza 11/12, \\ 80-233 Gdansk, Poland; azielins@pg.gda.pl
}

\title{
BIOCOMPATIBILITY AND BIOACTIVITY OF LOAD-BEARING METALLIC IMPLANTS
}

\begin{abstract}
The main objective of here presented research is to develop the titanium (Ti) alloy base composite materials possessing better biocompatibility, longer lifetime and bioactivity behaviour for load-bearing implants, e.g. hip joint and knee joint endoprosthesis. The development of such materials is performed through: modeling the material behaviour in biological environment in long time and developing of new procedures for such evaluation; obtaining of a $\mathrm{Ti}$ alloy with designed porosity; developing of an oxidation technology resulting in high corrosion resistance and bioactivity; developing of technologies for hydroxyapatite (HA) deposition aimed at composite bioactive coatings; developing of technologies of precipitation of the biodegradable core material placed within the pores.

The examinations of degradation of Ti implants are carried out in order to recognize the sources of both early allergies and inflammation, and of long term degradation. The theoretical assessment of corrosion is made assuming three processes: electrochemical dissolution through imperfections of the anodic oxide layer, diffusion of metallic ions through the oxide layer, and dissolution of oxides themselves.

In order to increase the biocompatibility, the toxic elements, aluminium ( $\mathrm{Al}$ ) and vanadium (V) are eliminated. The experiments have shown that titanium - zirconium - niobium (Ti-Zr-Nb) alloy may be a such a material which can also be prepared by both powder metallurgy $(\mathrm{P} / \mathrm{M})$ technique and selective laser melting. The porous (scaffold) Ti-Zr-Nb alloy is now obtained by powder metallurgy, classical and with space holders used before melting and decomposed, or remained during melting and removed by subsequent water dissolution. The oxidation of porous materials is performed either by electrochemical technique in special electrolytes or by chemical and/or hydrothermal method in order to obtain the optimal oxide layer well adjacent to an interface, preventing the base metal against corrosion and bioactive because of its nanotubular structure, permitting injection of some species into the pores. The $\mathrm{Ca}, \mathrm{O}$ and $\mathrm{N}$ ion implantation or deposition of zirconia sublayers may be used to increase the biocompatibility, bioactivity and corrosion resistance. The HA coating obtained by either electrophoretic, biomimetic or by sol-gel deposition should result in gradient structure similar to bone structure, possessing high adhesion strength. The core material of the porous material should result in a biodegradable material, allowing slower dissolution followed by stepwise growth of bone tissue and angiogenesis, preventing local inflammation processes, sustaining the mechanical strength close to that of non-porous material.
\end{abstract}

Keywords: biocompatibility, hydroxyapatite, implants, porous materials, titanium alloys 


\section{INTRODUCTION}

The biomaterials have been used since a long time. Generally, the load-bearing biomaterials must possess a sufficient strength, especially high fatigue strength and matched Young modulus, and low density. Table 1 shows a comparison of two parameters usually considered for hip joint endoprostheses [1]. They must demonstrate high corrosion resistance and biocompatibility for a long time period, and recently also bioactivity becomes important.

Table 1. Young modulus and density of some materials [1]

\begin{tabular}{|c|c|c|}
\hline Material & $\begin{array}{c}\text { Young modulus, E } \\
\mathrm{GPa}\end{array}$ & $\begin{array}{c}\text { Density, } \rho \\
\mathrm{g} / \mathrm{cm}^{3}\end{array}$ \\
\hline UHDPE & 0.5 & 0.95 \\
\hline PMMA & 3.0 & 1.18 \\
\hline Human compact bone (longitudinal) & 17 & 1.8 \\
\hline Dentin (ceramics) & $13-18$ & \\
\hline Enamel (ceramics) & $50-84$ & 7.86 \\
\hline Structural steel & 200 & 2.71 \\
\hline Concrete & 25 & 2.32 \\
\hline Aluminum & 70 & 0.61 \\
\hline Wood (pine) & 11 & \\
\hline
\end{tabular}

The biocompatibility can be considered as short and weak response of the immunologic system to a foreign body. In long time, biocompatibility can be considered as the extremely low degradation which prevents dissolution of metals or fragmentation of polymers or ceramics. For metals, this property is ranked as the highest for Ti alloys, then for Co alloys, Ni-Ti alloys and finally stainless steels, parallel to the corrosion resistance of the material. However, in real conditions the load-bearing implants are demanded to operate even for 15-25 years and so far there is neither knowledge on real degradation mechanisms, especially in conditions of frequent illnesses, which may appear at elderly age, nor suitable tests.

The most recently, bioactivity is another considered feature of biomaterials. Bioactivity as the faster growth of e.g. bone tissue by enhancement of adhesion of osteoblasts following the signals flowing from biological environment, means the faster and better incorporation of an implant with the body tissues. This paper is aimed to show how such bioactive material system possessing all necessary features, may be developed.

\section{LITERATURE SURVEY}

\section{Metallic biomaterials}

Among metallic biomaterials for long term bearing loaded implants, Ti and its alloys are assumed to be the best candidates. Their advantages include high corrosion resistance and biocompatibility, low density and high specific strength. The application of Ti and its alloys 
has also some limitations as: possible allergic and toxic effects [2], Young modulus higher that of a bone, sometimes low fatigue strength.

It is suggested that dissolution of the most popular Ti-6Al-4V alloy may initiate serious illnesses of central neural system, and even cancers $[3,4]$. Weak corrosion resistance at low $\mathrm{pH}$ value may, following inflammatory process, result even in loosening of an implant and in necessity of re-implantation. The suggested countermeasures include modification of the chemical composition of the alloys, change in structure of the oxide layer, thicker oxide layers, ion implantation, creation of composite and multiplex coatings on the alloys.

Among new alloys demonstrating properties better than those of Ti-6Al-4V alloy, as concerns the corrosion resistance and Young modulus, the following ones have been recommended: Ti-6Al-7Nb, Ti-6Al-6Nb-1Ta, Ti-5Al-2.5Fe, Ti-5Al-3Mo-4Zr, Ti-29Nb13 Ta-4.6Zr, Ti-13Nb-13Zr, Ti-15Mo, Ti-15Mo-5Zr-3Al, Ti-15Mo-3Nb-3Al-0.2Si, Ti$15 \mathrm{Mo}-3 \mathrm{Nb}-0.2 \mathrm{Si}$ Ti-15Mo-3Nb-3Al-0.3O, Ti-12Mo-6Zr-2Fe, Ti-7.5Mo-xFe, Ti-15Zr4Nb-4Ta, Ti-15Zr-4Nb-4Ta-0.2Pd, Ti-15Sn-4Nb-2Ta-0.2Pd [5].

\section{Scaffolds}

The bioactivity of Ti and its alloys is reached by different means. It is assumed that creation of porous structure increases the bone ingrowth rate in body fluids following the adhesion of osteoblasts. The deciding factor is the pore size. So far there are contradictory opinions on this issue. Generally, the pore size of $100-400 \mu \mathrm{m}$ is considered as necessary but lower pores size, 30-100 $\mu \mathrm{m}$, has been suggested as allowing the osteoblast migration. The greater pore size prefers the faster tissue growth, the smaller - greater adhesion strength. Certain effect on initiation of adhesion of osteoblasts have micropores and nanopores. Such effects can be achieved by changing the surface topography, including increase in roughness by micromachining or chemical etching or creation of nanocrystalline or amorphous structure [6].

Porous structures in a bulk or within the surface layer can be obtained by various methods: powder metallurgy $(\mathrm{P} / \mathrm{M})$ with or without space holders, rapid prototyping with an use of selective laser (SLM) or electron beam melting (EBM), plasma spraying, combustion, replication, etc. [6,7].

\section{Oxidation}

Corrosion resistance of $\mathrm{Ti}$ measured in electrochemical and gravimetric tests seems excellent: corrosion rate in simulated body fluids (SBF) changes between 0.01 and 0.1 $\mu \mathrm{g} / \mathrm{cm}^{2} *$ day, and after 48 weeks of an exposure of the Ti-6Al-4V alloy implant only traces of Ti, Al i V are found in body tissues [8]. However, in lactic and formic acids general corrosion occurs already after 3 weeks [9]. The Ti6Al4V, Ti6Al7Nb and Ti13Nb13Zr dissolve in phosphate buffered saline (PBS) [10]. Corrosion of the Ti6Al4V alloy appears after 7 days in saline and artificial saliva and exceeds that of the Ti15Zr4Nb4Ta alloy [11]. The titanium alloys are assumed as resistant to pitting but this corrosion form is observed in Ringer's solution at $37^{\circ} \mathrm{C}$ [12]. Passivation in $\mathrm{HNO}_{3}$ [13] and increase in roughness [14] magnify corrosion. The temperature, $\mathrm{pH}$, wear conditions influence the corrosion of $\mathrm{Ti}$ alloys [15]. 
Improvement of corrosion resistance and sometimes introducing the bioactivity of titanium and its alloys is achieved by different methods resulting in change in crystallinity degree, contribution of various crystalline forms of titania (morphology), structure and thickness of the oxide layer [16]. The formed oxides may be amorphous or crystalline, depending on anodic potential value and electrolyte $[17,18]$. The oxide film on pure Ti is composed of mainly $\mathrm{TiO}_{2}$ - either rutile or anatase, seldom brookite. An increase in thickness usually increase crystallinity. The crystallographic structure of titania composed mainly of anatase and possessing better corrosion resistance can be achieved by its formation with the PACVD technique from titanium tetrachloride [19].

Thicker oxide layers are obtained by a number of techniques: chemical oxidation [20-22], electrochemical oxidation [23,24], thermal and hydrothermal oxidation [20,25]. The layer properties are improved by annealing at $450-600^{\circ} \mathrm{C}$. Chemical oxidation is usually carried out in nitric acid with hydrogen peroxide or in sulphuric acid. The gaseous oxidation is performed in air or in oxygen at elevated temperatures. The hydrothermal oxidation results in formation of hydrated oxide layer in deionized water or in water vapour [25].

Electrochemical oxidation is usually performed at constant potential, constant current or by micro-arc oxidation [26]. The treatment of Ti alloys is carried out at constant or slowly changing values of current below breakdown potential in sulphuric, phosphoric, acetic, chromic acids and sometimes in alkali, resulting in adjustments of thickness, chemical composition and structure of layers $[17,26]$. The constant current or constant voltage techniques with an use of fluoric acid allow to obtain oxide layers composed of nanometric crystallites or amorphous islands [27-29]. The micro spark technique makes it possible to incorporate into the oxide layer the ions which can promote adhesion of osteoblasts, as calcium, phosphorous or oxygen ions [29].

\section{Deposition of hydroxyapatite}

Proper joining of bone tissue and metallic implant is often achieved by deposition of phosphate coating similar in chemical composition and mineralogical structure to the bone. As the phosphates, the HA ceramics, $\mathrm{Ca}_{10}\left(\mathrm{PO}_{4}\right)_{6}(\mathrm{OH})_{2}$, is mainly used, sometimes calcium triphosphate $\beta$-TCP $\left(\mathrm{Ca}_{3}\left(\mathrm{PO}_{4}\right)_{2}\right)$, and biphasic calcium phosphate $\mathrm{BCP}$ composed of HA and TCP $[30,31]$.

The deposition of HA is performed by different techniques: air or plasma spraying [32], sol-gel technique [33], magnetron sputtering [34], CVD [35], ion beam assisted deposition IBAD [36], pulsed laser deposition PLD [37], electrolytic and electrophoretic deposition [38].

In order to obtain better mechanical strength and adhesion the HA-based composite materials have been proposed. They contain reinforcing phases as: pure Ti [39], Ti6Al4V [40], titania [41], zirconia [42] and yttrium strengthened zirconium YSZ [43].

There are also proposed HA-based composite coatings with natural and synthetic polymers, like e.g. collagen [44] and chitosan [45]. The polymers have two functions: biodegradable compounds increase the degradation rate of the artificial phosphate and its substitution by the bone tissue, and may also increase the elasticity of brittle ceramics.

The thin bioglass coatings $\left(\mathrm{Na}_{2} \mathrm{O}-\mathrm{CaO}-\mathrm{P}_{2} \mathrm{O}_{5}-\mathrm{SiO}_{2}\right)$ are added to increase both adhesion and bioactivity [46]. The growth factors and anti-inflammatory substances can be introduced into phosphate coatings [47]. Recently, gradient coatings with mechanical properties 
changing fluently from the ceramics - implant interface to the HA surface have been developed [48].

\section{BIOACTIVE LOAD-BEARING MATERIAL SYSTEM}

\section{Bioactivity concept}

The bioactivity concept is here based on an assumption that substantial bioactivity, mechanical, chemical and physical properties can be obtained as the multicomponent biomimetic and partly biodegradable material is designed. The biomaterial/implant is gradually built as:

- Porous (scaffold) metallic non-toxic highly biocompatible alloy creating the matrix enhancing gradual growth of bone tissue (adhesion of osteoblasts and extracellular matrix formation) and angiogenesis;

- Artificial oxide layer increasing the corrosion resistance and introducing the bioactivity, improving adhesion between an implant and HA coating;

- HA-based coating further developing the bioactivity, and increasing the cohesion strength between an implant and a bone tissue;

- Core biodegradable material allowing slow growth of a bone tissue and simultaneously assuring the high and stable mechanical compression strength of the material system.

Such material system has some novel features and advantages as related to so far approach. The scaffold structure will be designed in order to optimize the chemical and mechanical properties; implant material will be highly non-allergic and non-toxic; metallic alloy will be especially protected for longer use; bioactivity will be reached by introducing the bioactive components in each of system parts, i.e. metallic material, oxide layer, HA coating, core material.

\section{Base scaffold material}

In order to select the base material the following criteria have been set:

- High corrosion resistance (high compatibility);

- Neglectable/unknown allergic and toxic reactions in human body;

- Ability to carry expected loads;

- Light weight.

Following this, the metallic implants, in general and specifically Ti alloys, seem the most appropriate or even the sole candidate materials. The ceramic materials are too brittle and polymer materials have too low mechanical strength to be used as a matrix. Among metallic materials the tantalum is less experienced material, the stainless steels and Ni-Ti alloys can provoke allergic reactions, Co alloys have lower corrosion resistance.

More than $30 \mathrm{Ti}$ alloys have been considered. The Ti-13Zr-13Nb alloy has been finally selected as the most suitable material: it contains neither $\mathrm{Al}$ nor $\mathrm{V}$ and it has one of the lowest Young modulus values and reasonable fatigue strength. 


\section{Fabrication of porous structure}

There is a variety of different fabrication methods of scaffold/porous materials. For the project the open cell porous structure should be obtained. Among different techniques the $\mathrm{P} / \mathrm{M}$ and SLM techniques have been chosen. The first technique is one of the cheapest and fast but it gives the random porous structures. The SLM method, more expensive and time consuming, is one of few methods resulting in perfectly arranged porous structures. Both methods utilize the powder as substrate.

In order to obtain the powder substrate two methods have been used. In first the powder has been produced by plasma melting of the metal and spraying it over the cooled surface. Generally, the powder size has been ranged between some micrometers and $250 \mu \mathrm{m}$. The second method is based on mechanical powdering by cutting. The elongated small grains are obtained.

The $\mathrm{P} / \mathrm{M}$ technique is performed without and with a use of space holders. In first tests the melting temperature, melting time and load applied have been determined. The mechanical alloying of the Ti-13Zr-Nb alloy in powder form has been proved to be possible as grains are joined together.

Two space holder groups are tested. From the classical space holders decomposing during melting process the thiourea and carbamide, and silicate and some $\mathrm{Zr}$ compounds as soluble space holders are investigated.

The SLM tests will be used to obtain: (i) uniform porous structure, (ii) gradient porous structure in the whole material, (iii) gradient porous structure with non-porous middle part of a specimen. The bioactivity and mechanical tests will decide which structure is the most suitable.

\section{Formation of oxide layer of enhanced corrosion resistance and bioactivity}

The presence of oxide layer on $\mathrm{Ti}$ base metal is the necessary condition for its corrosion resistance. The natural oxide layer has only some 5-15 $\mathrm{nm}$ of thickness and therefore the artificial oxidation is obligatory. For applied here porous Ti alloy following problems are important: (i) how to optimize the corrosion resistance, (ii) how to oxidize the alloy inside the pores, (iii) how to achieve both corrosion resistance and bioactivity, (iiii) which tests to use in order to assess the long term corrosion rate.

The optimization of an oxide layer cannot be simply considered as in increase in its thickness. The thicker oxide layer, the more imperfect; and thicker layers become brittle which can result in formation of cracks or delamination. Thus, the main focus is placed on such choice of techniques and parameters which result in oxide layers as resistant as possible.

So far studies have brought no answer which mechanism may be responsible for observed metalosis after long term exposure of the Ti implants in patients ' bodies. Three different mechanism are proposed: (i) corrosion caused by stepwise electrochemical reactions occurring within the corrosion tunnels as grain boundaries and other imperfections (cracks), (ii) diffusion of $\mathrm{Ti}$ and other metallic elements/ions through a lattice of $\mathrm{Ti}$ oxides, (iii) chemical dissolution of titania corrosion. The research is carried out to model all three mechanisms and determine the dissolution rate: high resolution SEM examinations of 
layers obtained by different techniques and parameters, calculation of permeation of metallic elements through the oxide barrier, and titania dissolution tests.

The key problem is the oxidation of base metal within the micropores. Such techniques have been never proposed and the most suitable approach is now looked for among electrochemical, chemical and hydrothermal methods. The principle idea is to oxidise the metal chemically or thermally to obtain the possible perfect layer and then to fabricate another nanotubular layer.

The formation of nanotubes is suitable as far as the bioactivity is concerned. On the other hand, the nanotubes may be considered as corrosion tunnels. The corrosion tests are made to clarify this problem. Generally, the nanotubes are formed above solid and thick oxide layer and they should not influence corrosion of the alloy. Fast corrosion may indeed damage the nanotubes and even create conditions to localized corrosion at the bulk - oxide layer interface.

The mechanical investigations and calculations with the FEM are carried out to determine whether such layers can be damaged under high stresses during surgery and later in a patient body. The closure of damaged nanotubes may drastically decrease their usefulness as bioactive layers and possible accumulators of e.g. antibiotics, growth factors or nanosilver being considered.

The unresolved problem is determination of alloy dissolution for implant remaining in the patient body for 15-20 years. The observed clinically degradation of Ti implants happens to more extent than expected. It may result from different reasons: (i) frequent local decrease in $\mathrm{pH}$ value brought by illnesses followed by (ii) surface damage of oxide layer and gradually increasing corrosion in later time period after implantation. The tests are elaborated which may assess the effects of stresses and $\mathrm{pH}$ during long time periods.

\section{Deposition of HA coatings}

The HA coatings are deposited on the metallic surfaces as they: (i) create the bioactivity, i.e. fast and efficient in-growth of a bone tissue, (ii) give the sufficient adhesion at the bone - implant interface.

When using nanotubular oxide layer, no intermediate thin HA coating are necessary and biomimetic, electrophoretic and sol/gel methods are investigated. As to clarify the effect of thickness, the nanointendation and FEM modelisation are carried out.

The bioactivity may be even enhanced by deposition of porous HA as a gradient HA obtained by electrophoretic technique. The tests are in the course to know whether such technique is good enough to create the HA coating within the pores of the Ti alloy.

The HA coating may be obtained as a composite coating. The composite coatings containing biologically active substances (antibiotics, growth factors), reinforcing compounds strengthening HA mechanically or making its further dissolution easier may be introduced but when using a core material, the simple HA coating may be sufficient.

\section{Fabrication of a core material}

Various materials are considered and investigated. The first concept is to use a mixture of HA and biodegradable polymer, like chitosan or collagen. Another idea is to use hydrogels. 
In both approaches, the sufficient compression strength may be achieved. The tests will be performed in future.

\section{CONCLUSION}

It is possible to produce a multicomponent material system which brings out the substantial bioactivity, mechanical, chemical and physical properties for new generation of porous composite load-bearing implants. In order to achieve the desired properties, it is necessary to obtain: (i) porous, metallic, non-toxic, highly biocompatible alloy, (ii) a nanotubular oxide layer within the pores of sufficient corrosion resistance and bioactivity, (iii) HA deposition in the pores, and (iv) core biodegradable material. The progress in fabrication of designed porous structures, oxidation of porous material, HA coatings' deposition on porous structures, and precipitation of a suitable core material is necessary.

\section{ACKNOWLEDGMENTS}

The research has been performed as a part of the Polish-Icelandic Project "Porous composite titanium alloy of high corrosion resistance, biocompatibility and bioactivity PORTAL” under ERA-NET MATERA Programme.

\section{REFERENCES}

1. http://silver.neep.wisc.edu/ lakes/BME315N3.pdf.

2. Zieliński A.: Nowoczesne biostopy tytanu i kierunki ich rozwoju. Materiały i Technologie (Materials and Technologies) 2 (2004) 242-247.

3. Świeczko-Żurek B.., Ziemlański A.: Allergies to implant metal compounds. Advances in Materials Science No. 3, 9 (2009) 39-46.

4. Malluche H.H.: Aluminium and bone disease in chronic renal failure. Nephrology Dialysis Transplantation 17 (2002) 21-24.

5. Domingo J.L.: Vanadium and diabetes. What about vanadium toxicity? Molecular and Cellular Biochemistry 203 (2000) 185-187.

6. Sobieszczyk S.: Optimal features of porosity of Ti alloys considering their bioactivity and mechanical properties. Advances in Materials Science No. 2, 10 (2010) 20-30.

7. Ryan G., Pandit A., Apatsidis D.P.: Fabrication methods of porous materials for use in orthopaedic applications. Biomaterials 27 (2006) 2651-2670.

8. Okazaki Y., Gotoh E., Manabe T., Kobayashi K.: Comparison of metal concentrations in rat tibia tissues with various metallic implants. Biomaterials 28 (2004) 5913-6025. 
9. M. Koike and H. Fuji, The corrosion resistance of pure titanium in organic acids, Biomaterials 22 (2001) 2931-2936.

10. M.A. Khan, R.L. Williams and D.F Williams, In-vitro corrosion and wear of titanium alloys in the biological environment. Biomaterials 17 (1996) 2117-2126.

11. Y. Okazaki and E. Gotoh, Comparison of metal release from various metallic biomaterials in vitro, Biomaterials 26 (2005) 11-21.

12. Landor I., Vavrik P., Sosna A., Jahoda D., Hahn H., Daniel M.: Hydroxyapatite porous coating and the osteointegration of the total hip replacement. Arch. Orthop. Trauma Surg. 127 (2007) 81-89.

13. Burstein G.T., Liu C., Souto R.M.: The effect of temperature on the nucleation of corrosion pits on titanium in Ringer's physiological solution. Biomaterials 26 (2005) 245-256.

14. Browne M., Gregson P.J.: Effect of mechanical surface pretreatment on metal ion release. Biomaterials 21 (2000) 385-392.

15. Zieliński A., Sobieszczyk S.: Corrosion of titanium biomaterials, mechanisms, effects and modelisation. Corrosion Reviews 26 (2008) 1-22.

16. Sobieszczyk S.: Self-organised nanotubular oxide layers on Ti and Ti alloys. Advances in Materials Science No. 2, 9 (2009) 25-41.

17. Carama O.R., Pauli C.P., Giordano M.C.: Potentiodynamic behavior of mechanically polished titanium electrodes. Electrochim. Acta 29 (1984) 1111-1117.

18. Felske A., Plieth W.J.: Raman spectroscopy of titanium dioxide layers. Electrochim. Acta 34 (1989) 75-77.

19. Głuszek J., Masalski J., Furman P., Nitsch K.: Structural and electrochemical examinations of PACVD $\mathrm{TiO}_{2}$ films in Ringer solution. Biomaterials 18 (1997) 789794.

20. Nishiguchi S., Kato H., Fujita H., Oka M., Kim H.-M., Kokubo T., Nakamura T.: Titanium metals form direct bonding to bone after alkali and heat treatments. Biomaterials 22 (2001) 2525-2533.

21. Wang X.-X., Hayakawa S., Tsuru K., Osaka A.: Bioactive titania gel layers formed by chemical treatment of $\mathrm{Ti}$ substrate with a $\mathrm{H}_{2} \mathrm{O}_{2} / \mathrm{HCl}$ solution. Biomaterials 23 (2002) 1353- 1357.

22. Takeuchi M., Abe Y., Yoshida Y., Nakayama Y., Okazaki M., Akagawa Y.: Acid pretreatment of titanium implants. Biomaterials 24 (2003) 1821-2827.

23. Sul Y.-T., Johansson C.B., Petronis S., Krozer A., Jeong Y., Wennerberg A., Albrektsson T.: Characteristics of the surface oxides on turned and electrochemically oxidized pure titanium implants up to dielectric breakdown: the oxide thickness, micropore configuration, surface roughness, crystal structure and chemical composition. Biomaterials 23 (2002) 491-501. 
24. Frauchiger V.M., Schlottig F., Gasser B., Textor M.: Anodic plasma-chemical treatment of CP titanium surfaces for biomedical applications. Biomaterials 25 (2004) 593-606.

25. MacDonald D.E., Rapuano B.E., Deo N., Strancik M., Somasundaran P., Boskey A.L.: Thermal and chemical modification of titanium-aluminum-vanadium implant materials: effects on surface properties, glycoprotein adsorption, and MG63 cell attachment. Biomaterials 25 (2004) 3135-314.

26. Yang B., Uchida M., Kim H.-M., Zhang H., Kokubo T.: Preparation of bioactive titanium metal via anodic oxidation treat ment. Biomaterials 25 (2004) 1003-1010.

27. Felske A., Plieth W.J.: Raman spectroscopy of titanium dioxide layers. Electrochim. Acta 34 (1989) 75-77.

28. Zhu X., Kim K.-H., Jeong J.: Anodic oxide films containing Ca and P of titanium biomaterial. Biomaterials 22 (2001) 2199-2206.

29. Krasicka-Cydzik E.: Gel-like layer development during formation of thin anodic films on titanium in phosphoric acid solutions. Corrosion Sci. 46 (2004) 2487-2502

30. Sobieszczyk S.: Hydroxyapatite coatings on porous $\mathrm{Ti}$ and $\mathrm{Ti}$ alloys. Advances in Materials Science No. 1, 10 (2010) 19-28.

31. Sobieszczyk S., Zieliński A.: Coatings in arthroplasty. Advances in Materials Science No. 4, 8 (2008) 35-54.

32. Mohammadi Z., Ziaei-Moayyed A.A., Sheikh-Mehdi Mesgar A.: Adhesive and cohesive properties by indentation method of plasma-sprayed hydroxyapatite coatings. Applied Surface Science 253 (2007) 4960-4965.

33. Stoch A., Jastrzębski W., Długoń E., Lejda W., Trybalska B., Stoch G.J., Adamczyk A.: Sol-gel derived hydroxyapatite coatings on titanium and its alloy Ti6A14V. Journal of Molecular Structure 744-747 (2005) 633-640.

34. Yamaguchi T., Tanaka Y., Ide-Ektessabi A.: Fabrication of hydroxyapatite thin films for biomedical applications using RF magnetron sputtering. Nuclear Instruments and Methods in Physics Research B 249 (2006) 723-725.

35. Giavaresi G., Ambrosio L., Battistion G.A., Casellato U., Gerbasi R., Finia M., Aldini N.N., Martini L., Rimondini L., Giardino R.: Histomorphometric, ultrastructural and microhardness evaluation of the osseointegration of a nanostructured titanium oxide coating by metal-organic chemical vapour depostion: an in vivo study. Biomaterials 25 (2004) 5583-5591.

36. Lee I-S., Zhao B., Lee G-H., Choi S-H., Chung S-M.: Industrial application of ion beam assisted deposition on medical implants. Surface and Coatings Technology 201 (2007) 5132-5137.

37. Kim H., Camata R.P., Lee S. i in.: Crystallographic texture in pulsed laser deposited hydroxyapatite bioceramic coatings. Acta Mater. 55 (2007) 131-139.

38. Mayr H., Ordung M., Ziegler G.: Development of thin electrophoretically deposited hydroxyapatite layers on Ti6Al4V hip prosthesis. Journal of Material Science 41 (2006) 8138-8143. 
39. Zheng X., Huang M., Ding Ch.: Bond strength of plasma-sprayed hydroxyapatite/Ti composite coatings. Biomaterials 21 (2000) 841-849.

40. Khor K.A., Gu Y.W., Pan D., Cheang P.: Microstructure and mechanical properties of plasma sprayed HA/YSZ/Ti-6Al-4V composite coatings. Biomaterials 25 (2004) 40094017.

41. Lu Y-P., Li M-S., Li S-T., Wang Z-G., Zhu R-F.: Plasma-sprayed hydroxyapatite +titania composite bond coat for hydroxyapatite coating on titanium substrate. Biomaterials 25 (2004) 4393-4403.

42. Chou B-Y., Chang E.: Plasma-sprayed hydroxyapatite coating on titanium alloy with $\mathrm{ZrO}_{2}$ second phase and $\mathrm{ZrO}_{2}$ intermediate layer. Surface and Coating Technology 153 (2002) 84-92.

43. Fu L., Khor K.A., Lim J.P.: The evaluation of powder processing on microstructure and mechanical properties of hydoxyapatite (HA)/yttria stabilized zirconia (YSZ) composite coatings. Surface and Coatings Technology 140 (2001) 263-268.

44. Liao S., Watari F., Zhu Y., Uo M., Akasaka T., Wang W., Xu G., Cui F.: The degradation of the three layered nano-caronated hydroxyapatite/collagen/PLGA composite membrane in vitro. Dental Materials 23 (2007) 1120-1128.

45. Wang L., Li Ch.: Preparation and physicochemical properties of a novel hydroxyapatite/chitosan - silk fibroin composite. Carbohydrate Polymers 68 (2007) 740-745.

46. F.L.S., Borges Ch.S., Branco J.R.T., Pereira M.M.: Structural analysis of hydroxyapatite/bioactive glass composite coatings obtained by plasma spray processing. Journal of Non-Crystalline Solids 247 (1999) 64-68.

47. Jansen J.A., Vehof J.W.M., Ruhe P.Q., et al.: Growth factor-loaded scaffolds for bone engineering. Journal of Controlled Release 101 (2005) 127-136.

48. Eliaz N., Sridhar T.M., Kamachi Mudali U., Raj B.: Electrochemical and electrophoretic deposition of hydroxyapatite for orthopaedic. Surface Engineering No. 3,21 (2005) 238-242. 